\title{
The effect of intrinsic and extrinsic factors on flower constancy in stingless bees
}

\author{
Ester Judith SlaA*, Ayco J.M. TACK, Marinus Jan SOMMEIJER \\ Department of Behavioural Biology, Utrecht University, PO Box 80.086, 3508 TB Utrecht, The Netherlands
}

(Received 9 January 2003; revised 13 March 2003; accepted 24 March 2003)

\begin{abstract}
To enhance our understanding of the variability of flower constancy, we studied the influence of foraging conditions on the level of individual constancy in two species of stingless bees, Trigona dorsalis and Oxytrigona mellicolor, using a dimorphic artificial flower patch with equal reward in both flower types. Flower constancy increased greatly when the flower types were more dissimilar, and then approached constancy levels found for European honey bees. Sugar concentration had little effect on flower constancy. The presence of nestmates enhanced flower constancy somewhat in $O$. mellicolor but not in $T$. dorsalis, probably because of species-specific differences in local enhancement. The individual variability within treatments could be explained partly by individual variation in foraging tempo, with faster foraging leading to higher flower constancy.
\end{abstract}

flower constancy / foraging conditions / stingless bee

\section{INTRODUCTION}

Many flower-visiting insects are known to visit flowers in an individually constant way, i.e. they tend to restrict their visits to one flower type for a certain time, bypassing other equally rewarding flower types in the process (e.g. Darwin, 1876; Waser, 1986; Chittka et al., 1999). Different species seem to differ in their level of flower constancy (e.g. Grant, 1950), although comparative studies with several species under equivalent experimental set-up are rare (Bateman, 1951; Goulson and Wright, 1998; Slaa et al., 1998a). When insect species are compared, the European honey bee (Apis mellifera) seems to be much more constant than all other species studied up to now, including other honey bee species (Wells and Rathore, 1994) and stingless bees (Slaa et al., 1998a).

Despite of apparent species-specific differences, flower constancy is also a very flexible behaviour, which has led to contradictory results on flower constancy in A. mellifera (Wells and Wells, 1984; Hill et al., 1997). Although the mechanisms and causes of flower constancy are not well understood, it is known that both factors intrinsic to the forager, e.g. learning and memory dynamics, and factors extrinsic to the forager, e.g. floral morphology and patch type, affect flower choice behaviour (reviewed in Chittka et al., 1999). Interaction among these factors probably explains much of the variation found in flower constancy. To be able to establish a speciesspecific degree of flower constancy and compare species, the variability of flower constancy has to be understood first.

The effects of some extrinsic factors on flower constancy, such as pre-training (Banschbach, 1994; Hill et al., 1997), flower organisation (inflorescence versus single pedicellated flowers: Waddington and Holden, 1979; Wells and Wells, 1984), and floral

\footnotetext{
* Corresponding author: e.j.slaa@bio.uu.nl
} 
colour (Hill et al., 2001) have now been documented. In addition, flower constancy seems to be positively related to reward quantity (Chittka et al., 1997; Goulson et al., 1997, but see Wells and Wells, 1984). The effect of sugar concentration on flower constancy, when the available flower types offer the same reward, is largely unknown. Nevertheless, different studies use different rewards, ranging from $20 \%$ to $50 \%$ (e.g. Banschbach, 1994; Slaa et al., 1998b). Individuals of A. mellifera still show nearly $100 \%$ fidelity when floral reward concentration is $34 \%$ (Hill et al., 1997) but the effect of lower sugar concentrations has not been tested.

Individual flower choice can also be influenced by the presence of nestmates through direct attraction or avoidance based on visual and/or olfactory cues, referred to as local enhancement (Thorpe, 1956; social wasps: Raveret Richter 2000; flies: Propoky et al., 2000; stingless bees: Slaa et al., 2003). Because the degree of local enhancement differs among species (Slaa et al., 2003), the effect of nestmates on individual flower constancy may be species-specific. However, some studies on flower constancy allow several nestmates to forage simultaneously (e.g. Wells et al., 1992; Wells and Rathore, 1994; Slaa et al., 1998a), whereas other studies do not.

Previous studies show that flower constancy in honey bees and bumble bees increases with decreasing visual similarity between the flower species (Grant, 1950; Bateman, 1951; Waser 1986; Chittka et al., 2001; Hill et al., 2001). In addition to visual cues, bees also perceive and use olfactory cues in floral choice (von Frisch, 1919; Laska et al., 1999). Natural flowers can differ in one or both of these modalities, but the influence of the number of differing modalities on flower constancy has not been studied.

This study aims at gaining a better understanding of the variability of flower constancy and investigates the effect of several extrinsic factors, which may change under natural foraging conditions, on flower constancy: (1) sugar concentration of the nectar, (2) presence of nestmates on the patch, and (3) floral similarity, defined by the number of differing perceptual modalities. In addition, we tested whether two factors intrinsic to the forager, colour preference during the experiment and foraging tempo, could account for variation within each treatment. We used two closely related stingless bee species, Oxytrigona mellicolor and Trigona dorsalis, similar in appearance but different in colony size, foraging strategy and local enhancement, to assess whether treatment effects were species-specific. This study is the first to experimentally analyse the effects of various intrinsic and extrinsic factors on flower constancy in nonApis flower visitors.

\section{MATERIALS AND METHODS}

\subsection{Study site and bee species}

The experiments were conducted in Pozo Azul de Abangares, Guanacaste province, Costa Rica $\left(10^{\circ} 10^{\prime} 24^{\prime \prime} \mathrm{N}, 85^{\circ} 00^{\prime} 24^{\prime \prime} \mathrm{W}\right.$; altitude $\left.170 \mathrm{~m}\right)$. Two species of stingless bees (Apidae: Meliponini) were used: Trigona (Tetragona) dorsalis ziegleri Friese and Oxytrigona mellicolor Packard. Individuals of these species are similar in body size $(6-7 \mathrm{~mm})$ and colour (mainly yellowish); however the species differ in number of bees per colony (on average 1800 and 5500 individuals respectively: Roubik, 1983) and foraging strategy (Hubbell and Johnson, 1978; Johnson, 1983; Slaa, 2003). T. dorsalis is a solitary foraging species and foragers are neither attracted nor repelled by foraging nestmates. $O$. mellicolor is a mass-recruiter, and foragers are highly attracted to each other (Slaa et al., 2003). One wild colony of each species was used. Although we did not measure colony strength directly, both colonies showed normal foraging activity, and were still alive 16 months after the end of the study.

\subsection{General procedure experiments}

\subsubsection{Flower patch}

For each experiment, an artificial flower patch was used that contained 36 flowers $(3 \times 3 \mathrm{~cm}$ Plexiglas flower head on a pedicel $9 \mathrm{~cm}$ high) of two types (18 flowers of each type; for details see Slaa et al., 1998a). Flowers were arranged alternately in a $6 \times 6$ Cartesian grid, spaced $10 \mathrm{~cm}$ apart, on a green polystyrene foam board $(60 \times 60 \mathrm{~cm})$. Each flower offered a surplus $(78 \mu \mathrm{L})$ of $50 \% \mathrm{w} / \mathrm{w}$ sugar solution, hereafter called "nectar", as a reward, unless otherwise stated. The flower types could differ in colour (yellow versus blue) and/or odour (essential oils added to the nectar 
(50 $\mu \mathrm{L} / \mathrm{L})$ : aniseed versus rosewood). Nectar could differ in quality between and within experiments, but was always equal for the two flower types at a given time.

According to bee colour perception, the yellow and blue flowers used in our experiments differ perceptually for the bees, and both colours are equally distinguishable from the green background of the patch (Slaa, 2003). Bees possess excellent odour discrimination abilities (e.g. Laska et al., 1999) and the behavioural data of this study indicate that bees did perceive the two odours as different.

\subsubsection{Pre-training}

Bees were pre-trained to the experimental site, located $10 \mathrm{~m}$ from the nest tree, using a transparent micro-titre plate containing the same nectar as the bees would encounter during their first visit to the patch. At the experimental site, one bee was colour marked and all other visitors were captured unless otherwise stated. The test bee was allowed to make various trips to the experimental site before the training plate was substituted by the flower patch. In experiment 3 , an odourless $50 \%$ sucrose solution was used during pre-training to maintain bees experimentally naive with regard to odour. Future test bees were colour marked and restrained from foraging during experiment 3 to prevent the possible transfer of odour information from the foraging test bee to future test bees.

\subsubsection{Data collection}

Bees were tested individually to avoid possible interfering effects of other foragers on flower choice, unless otherwise stated. All test bees were experimentally naive to the flower patch prior to the experiment, and were allowed to make 30 foraging trips to the patch unless otherwise stated. To prevent the possibility of flower constancy due to constancy to a specific location of the patch, the patch was turned clockwise after every foraging trip. Flower choice and round trip time were recorded for each foraging trip. In addition, patch time (time spent foraging on the patch during one foraging trip) and extra-patch time (time spent away from the patch between two successive foraging trips) were recorded in experiments 2 and 3 . Individuals only needed to visit one flower to obtain a full nectar load and only the first flower visit of a foraging trip during which the bee actually imbibed nectar (indicated by bobbing of the abdomen) was included in the analyses. The degree of flower constancy was calculated by division of the number of successive visits to the same flower type by the total number of successive visits (Constancy Index; for details see Slaa et al., 1998a). This index ranges from 0 (strictly alternating sequences) through 0.5 (random choice) to 1 (completely constant foraging).

Experiment 1 was conducted from March to May 1998 (effect sugar concentration on flower constancy) and in August and September 1999 (concentration preferences). Experiments 2 and 3 were conducted from August to December 2000).

\subsection{Experiment 1: the effect of reward quality on flower constancy}

In tests of the influence of reward quality on flower constancy, flower types differed in colour (yellow and blue) but had a common odour (peppermint). The two flower types were never different in reward quality or quantity at any one time. Individual constancy was measured in two groups of bees ( $N=10$ for each group); individuals of the first group initially foraged on flowers with a high quality reward which decreased subsequently after every 30 foraging trips in both flower types (50\%-35\%-20\%) and individuals of the second group initially foraged on flowers with a low quality reward which increased subsequently after every 30 foraging trips in both flower types (20\%-35\%$50 \%$ ). Individual flower constancy indices were calculated for each sugar concentration (three flower constancy indices per individual).

Because changes in sugar concentration did not elicit changes in foraging behaviour, we tested whether $O$. mellicolor and $T$. dorsalis actually perceive absolute differences of $15 \%$ in sugar concentration (20\%-35\%-50\%). During pre-training, 35\% peppermint-scented nectar in a transparent feeder was used. During training, the forager encountered one yellow flower or one blue flower alternately on successive foraging trips, which both offered peppermint-scented nectar but differed in sugar concentration of the nectar $(20 \%$ and $35 \%$ or $35 \%$ and $50 \%$ ). After 10 trips, or when the bee was reluctant to drink from the flower type with the lowest sugar concentration, the bee was offered a dual choice between the two rewarding flower types and all flower choices were recorded during the subsequent 11 trips $(N=12$ for each dual choice situation). Because $O$. mellicolor did not differentiate between $35 \%$ and $50 \%$, the experiment was repeated with training on $50 \%$ instead of $35 \%$ nectar for both species.

\subsection{Experiment 2: the effect of local enhancement on flower constancy}

In tests of the influence of local enhancement on flower constancy, flowers differed in colour (yellow and blue) but had a common odour (peppermint). Individual constancy was measured in two 
groups of bees ( $N=10$ for each group); in the first group test bees foraged alone on the patch whereas in the second group nine nestmates were also allowed to forage on the patch. In addition to the flower choices of the test bee, we recorded the number of nestmates present at the patch at the time of flower choice. If nestmates were present, we recorded whether the test bee landed on a same flower as where a nestmate was present (i.e. an occupied flower).

\subsection{Experiment 3: the effect of floral similarity on flower constancy}

To test for the influence of floral similarity on flower constancy, individual flower constancy levels of bees foraging on flowers that differed in one floral cue were compared with those foraging on flowers that differed in two floral cues of different perceptual modalities $(N=10$ for each group). Bees of the first group chose between flower types that differed in colour (yellow and blue) but that were equal in odour (aniseed or rosewood, $N=5$ for each odour). The second group chose between flower types that differed in odour (aniseed and rosewood) but were equal in colour (yellow or blue, $N=5$ for each colour). The third group chose between flower types that differed in both odour and colour (yellow \& peppermint and blue \& rosewood or yellow \& rosewood and blue \& peppermint, $N=5$ for each combination).

\subsection{Inter- and intra-specific variance in flower constancy}

To test for the effect of intrinsic factors on intraspecific variability, two behavioural parameters that varied among individuals, foraging tempo and colour preference, were tested for correlation with the degree of constancy. Only individuals from experiments 2 and 3 that foraged alone on flowers that differed only in colour were used in the analyses. Individuals that visited more than one flower during their first trip were excluded.

\subsection{Statistics}

To test for treatment and species effects, and possible interaction effects between treatment and species, a two-way ANOVA was applied followed by the post-hoc Tukey HSD test for comparisons among treatments, given that the data were distributed normally (tested for with the KolmogorovSmirnov test) and variance did not differ significantly between the groups (tested for with Levene's test of equality of error variances). If these criteria were not met, differences between the two species and the treatments were analysed separately with the Mann-Whitney U test (two groups) or the Kruskall-Wallis test (> two groups). To test whether changes in sugar concentration affected the level of individual flower constancy, the Friedman analysis of variance by ranks was used. To test for preferences in sugar concentration, the Wilcoxon signed ranks test was used. To test for local enhancement, the observed frequencies of an individual landing on an occupied flower were compared with the expected frequencies under random foraging, using a Wilcoxon signed-rank test. Test bees of $O$. mellicolor generally visited every part of the patch equally, so that the expected frequency is simply given by: (total number of nestmates present on the patch during the 30 bouts)/36. Test bees of $T$. dorsalis generally restricted their visits to one side of the patch. To correct for this side preference, we divided the patch in four equal quarters of nine flowers each, resulting in four absolute positions. For each absolute position the expected frequency of landing on the occupied flower was calculated by: (total number of nestmates present on the patch during the 30 bouts) * (proportion of visits to the respective quarter $)^{2} / 9$. These expected frequencies of the four absolute positions were summed and compared with the observed frequency for that individual as described above. The Chi-square test or the Binomial test (expected values $<5$ ) was used to analyse the effect of extra-patch time after the first visit on flower choice in the second visit. The Wilcoxon signed-ranks test was used to analyse the relation between the tendency to switch and preceding extra-patch time for all successive trips. The effect of colour preference on flower constancy was tested for significance using the Pearson correlation test.

\section{RESULTS}

In all experiments, each species visited both flower types present, with different preferences among the individuals. This indicates that the constancy indices calculated in this study are not due to fixed, species-specific, preferences for one of the types.

\subsection{Experiment 1: the effect of reward quality on flower constancy}

Sugar concentration had little influence on individual flower constancy levels when both flower types offer the same sugar concentration (Fig. 1). Bees that started foraging on rewards of $20 \%$ nectar were as constant as bees that started foraging on $50 \%$ nectar 


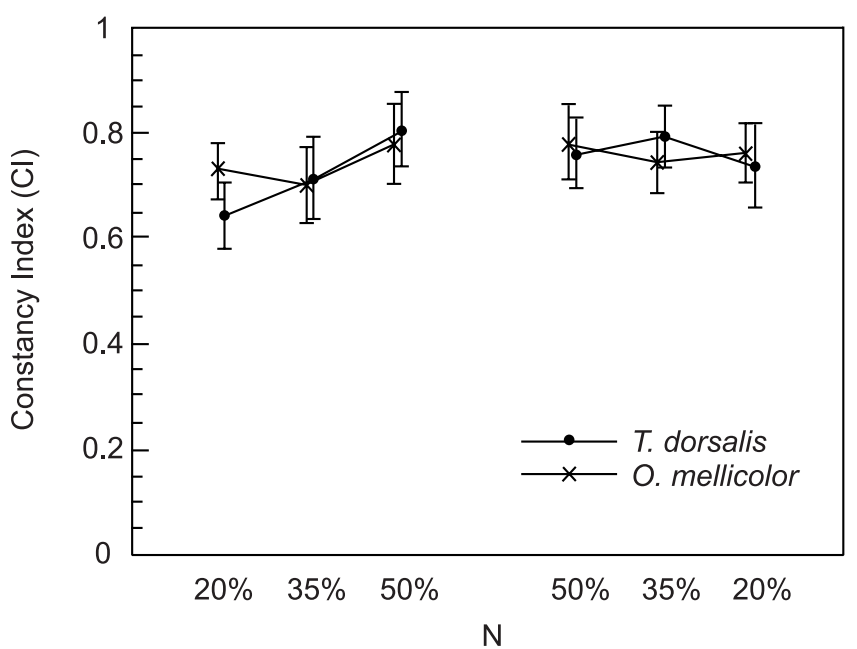

Figure 1. Flower constancy on colour $(\mathrm{CI} \pm \mathrm{SE})$ as a function of an increase (left part, $N=10$ ) or decrease (right part, $N=10$ ) in sugar concentration. Sugar concentration changed in all flowers so that the reward quality at any given time was equal for the two flower types. Individuals foraged for 30 trips on each concentration. during their first 30 trips (Mann-Whitney U test: $U=152, N_{1}=N_{2}=20, P=0.20$ ), without differences between the species (MannWhitney U test: $U=164.5, N_{1}=N_{2}=20$, $P=0.34$ ). A subsequent decrease in sugar concentration from $50 \%$ to $35 \%$ and $20 \%$ did not affect constancy levels (Friedman analysis of variance by ranks, $d f=2, N=10 ; T$. dorsalis: $X^{2}=0.24, P=0.89 ;$ O. mellicolor: $X^{2}=$ $1.6, P=0.44)$. Increases in sugar concentration from $20 \%$ to $35 \%$ and $50 \%$ significantly affected flower constancy in $T$. dorsalis $\left(X^{2}=7.6, P=0.02\right)$, where constancy levels increased significantly, but not in $O$. melli$\operatorname{color}\left(X^{2}=2.7, P=0.26\right)$.

In the dual choice experiment, bees generally preferred the higher sugar concentration. When choosing between $20 \%$ and $35 \%$, both species had a significant preference for $35 \%$ (T. dorsalis: average $\pm \mathrm{SD}=82 \pm 9 \%$, Wilcoxon signed ranks test: $N_{-}=0 N_{+}=12$, $P=0.002 ; O$. mellicolor: average $\pm \mathrm{SD}=84 \pm$ $15 \%$, Wilcoxon signed ranks test: $N_{-}=0$, $\left.N_{+}=12, P=0.002\right)$. However, when choosing between $35 \%$ and $50 \%$ only $T$. dorsalis had a significant preference for $50 \%$ ( $T$. dorsalis: when trained with $35 \%$ average $\pm \mathrm{SD}=$ $83 \pm 9 \%$, Wilcoxon signed ranks test: $N_{-}=0$ $N_{+}=12, P=0.002$; when trained with $50 \%$ average $\pm \mathrm{SD}=84 \pm 9 \%$, Wilcoxon signed ranks test: $N_{-}=0 N_{+}=12, P=0.002 ; O$. mellicolor: when trained with $35 \%$ average \pm SD $=$ $54 \pm 27 \%$, Wilcoxon signed ranks test: $N_{-}=4$,
$N_{+}=8, P=0.50$; when trained with $50 \%$ average $\pm \mathrm{SD}=49 \pm 27 \%$, Wilcoxon signed ranks test: $N_{-}=5, N_{+}=6, P=0.82$ ). Therefore we can conclude that $T$. dorsalis did perceive both experimentally induced reward changes in the experiment described above, and that $O$. mellicolor perceived at least the difference between $20 \%$ and $35 \%$.

\subsection{Experiment 2: the effect of local enhancement on flower constancy}

Oxytrigona mellicolor showed local enhancement, visiting occupied flowers more than expected under random foraging $(2.1 \pm$ 1.5 times more than expected, Wilcoxon signed-ranks test: $T=2.19, N=10, P=0.028$ ). Test bees of $T$. dorsalis did not show local enhancement (Wilcoxon signed-ranks test: $T=1.27, N=10, P=0.203)$.

The effect of the presence of nestmates on flower constancy was species-specific (two-way ANOVA, Species X Treatment: $\left.F_{1,36}=4.23, P=0.047\right)$. In $O$. mellicolor, the presence of nestmates increased individual constancy levels (Fig. 2; Mann-Whitney U test, $\left.\quad U=23.5, \quad N_{1}=N_{2}=10, \quad P=0.043\right)$. Apparently, local enhancement does not overrule flower constancy but rather enhances flower constancy, which is supported by the observation that bees landed more on an occupied flower of the preferred colour than on an occupied flower of the other colour (Wilcoxon 


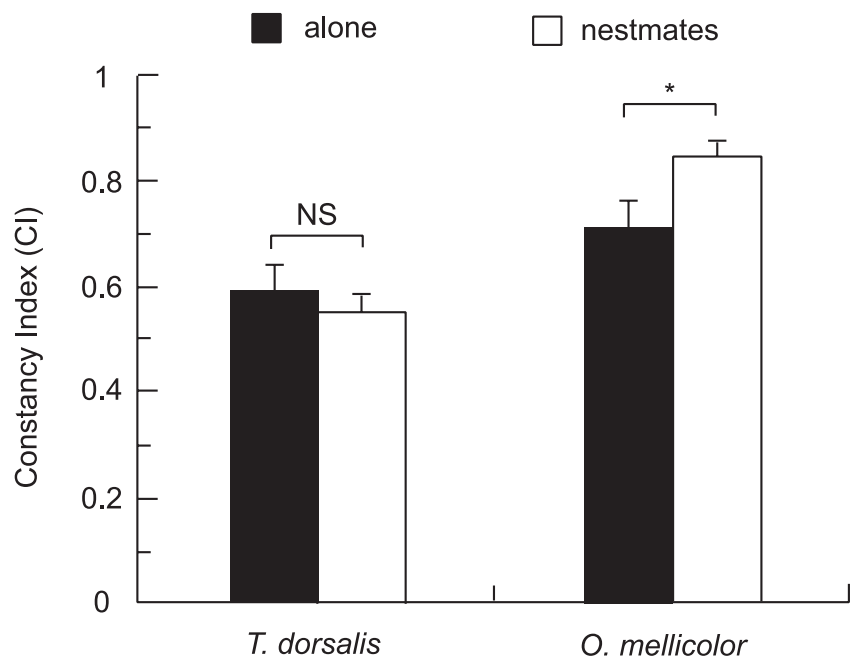

Figure 2. Flower constancy on colour $(\mathrm{CI}+\mathrm{SE})$ in relation to the presence of nest mates for $T$. dorsalis (left) and $O$. mellicolor (right). $N=10$ for each group. NS: not significant. *: $P<0.05$.

signed-ranks test: $T=2.37, N=9, P=0.018$ ). In $T$. dorsalis, the species that did not show local enhancement, the presence of nestmates did not affect flower constancy (Fig. 2; MannWhitney U test, $U=42.5, N_{1}=N_{2}=10, P=$ $0.58)$.

\subsection{Experiment 3: the effect of floral similarity on flower constancy}

When flower types differed in one cue (odour or colour), bees were on average only moderately constant to one of the types (Fig. 3). Flower constancy was significantly affected by the nature of the floral types (twoway ANOVA, Treatment: $F_{2,54}=45.3, P<$ $0.005)$ without differences between the species (Species: $F_{1,54}=2.26, P=0.139$ ) and without significant species-specific treatment effects (Species X Treatment: $F_{2,54}=3.14$, $P=0.051)$. The level of flower constancy when flowers only differed in colour was not significantly different from the level of flower constancy when flowers only differed in odour (Fig. 3, Tukey HSD test, $P=0.98$ ). Flower constancy was significantly higher when flowers differed in both odour and colour, compared to only odour differences (Tukey HSD test, $P<0.005)$ or only colour differences (Tukey HSD test, $P<0.005$ ).

\subsection{The effect of intrinsic factors on flower constancy}

Bees foraging alone on a highly rewarding patch $(50 \%)$ with flower types differing only in colour differed highly in their level of constancy, ranging from completely random to completely constant foraging. Comparison of the three experiments reveals that both species and experiment were significant sources of variation (two-way ANOVA, Experiment: $F_{2,54}=5.7, P=0.005$, Species: $F_{2,54}=6.6$, $P=0.013$, Experiment X Species: $F_{2,54}=0.58$, $P=0.57)$. O. mellicolor was significantly more constant than $T$. dorsalis $(\mathrm{CI} \pm \mathrm{SD}=$ $0.73 \pm 0.18$ and $0.62 \pm 0.19$ respectively), and overall constancy in experiment 1 was higher than in experiments 2 and $3\left(\mathrm{CI}_{\exp 1} \pm \mathrm{SD}=\right.$ $0.78 \pm 0.20 ; \mathrm{CI}_{\text {exp2 }} \pm \mathrm{SD}=0.65 \pm 0.16$; $\mathrm{CI}_{\text {exp3 }} \pm \mathrm{SD}=0.59 \pm 0.17$; Tukey HSD test, exp1-2: $P=0.07$, exp 1-3: $P=0.004)$. The species also differ significantly in constancy when experiment 1 is not taken into account $\left(\mathrm{CI}_{\mathrm{Om}} \pm \mathrm{SD}=0.70 \pm 0.16 ; \mathrm{CI}_{\mathrm{Td}} \pm \mathrm{SD}=0.55 \pm\right.$ 0.14; ANOVA, $\left.F_{1,38}=9.142, P=0.004\right)$.

\subsubsection{Foraging tempo}

The tendency to switch flower types during the first two visits was related to the 

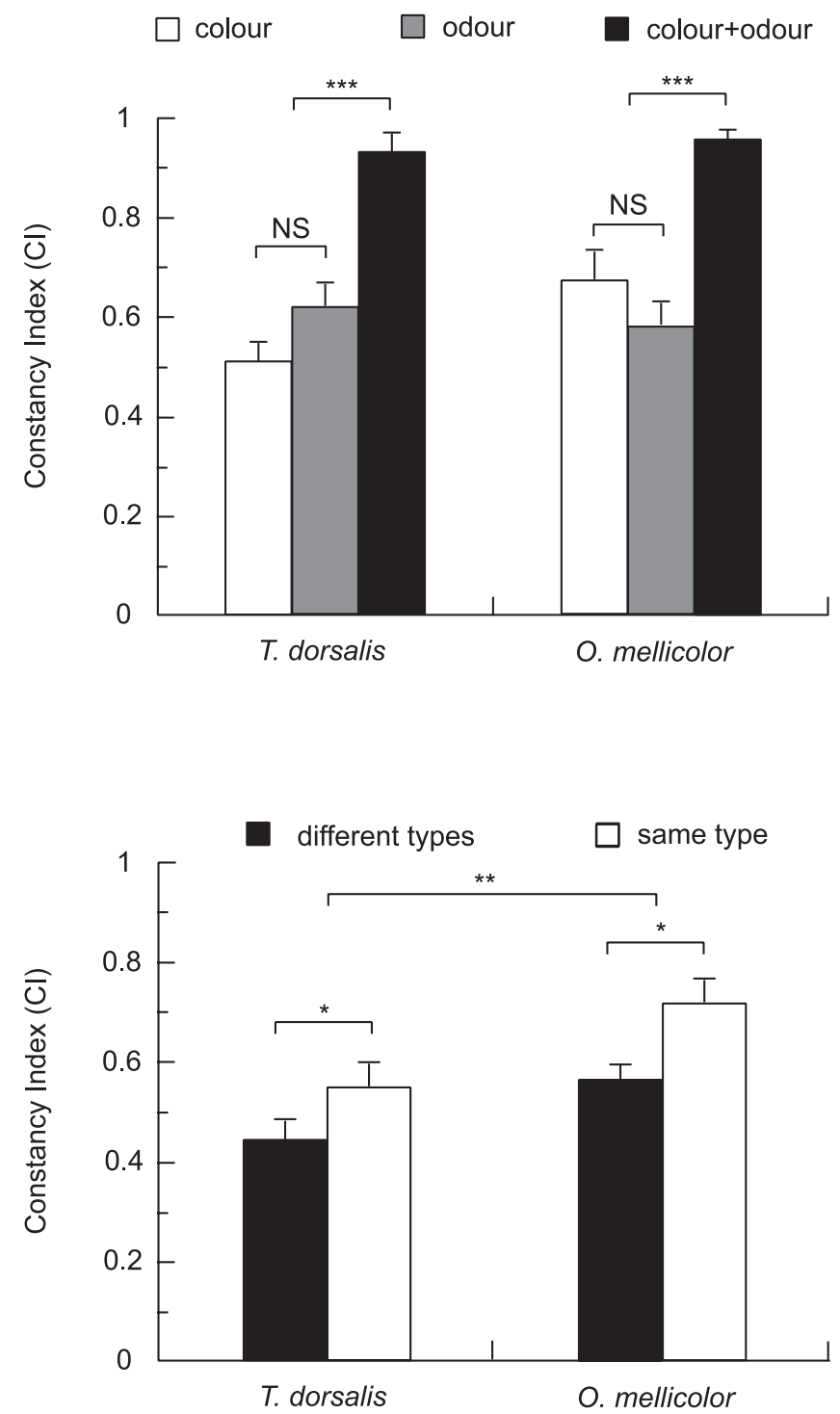

Figure 3. Flower constancy (CI $+\mathrm{SE})$ in relation to floral similarity for T. dorsalis (left) and O. mellicolor (right). Individual foragers visited flowers that differed in one cue (odour or colour) or in two cues (odour and colour). $N=10$ for each group. NS: not significant. $* * * P<$ 0.005 .

Figure 4. The influence of initial flower choice on flower constancy. Comparison of flower constancy on colour $(\mathrm{CI} \pm \mathrm{SE})$ between foragers that during their initial two visits to the patch visited two different types ( $N=12$ for $T$. dorsalis, $N=8$ for $O$. mellicolor) and foragers that choose the same type $(N=18$ for T. dorsalis, $N=22$ for $O$. mellicolor $) . * P<0.05, * * P<$ 0.01 . extra-patch time between these first two visits. Individuals that spent less than 125 seconds away from the patch before choosing their second flower were significantly more likely to choose the same flower type (Chi-square test, $d f=1, X^{2}=6.4, P=0.01$ for $O$. mellicolor, $X^{2}=4.45, P=0.03$ for $T$. dorsalis), whereas individuals that spent longer than 125 seconds away from the patch chose equally between the last visited and the other flower type (Binomial test, $P=0.25, N=10$ for $O$. mellicolor, $P=0.16, N=5$ for $T$. dorsalis). In addition, individuals that switched flower types during the first two trips became less constant than individuals that did not switch flower types during the first two trips (twoway ANOVA, Nature visits: $F_{1,29}=6.8$, $P=0.014$, Nature $X$ Species: $F_{1,29}=0.01$, $P=0.92$; Species: $\mathrm{F}_{1,29}=8.444, \mathrm{P}=0.007$; Fig. 4). The observed relation between tendency to switch and preceding extra-patch time did not hold when all successive trips 
were analysed together (Wilcoxon signedranks test, $T=0.60, N=19, P=0.55$ for $O$. mellicolor and $T=0.19, N=20, P=0.85$ for T. dorsalis).

The differences in flower constancy among the three experiments (see above) can be explained by differences in foraging tempo. Individuals from experiment 1 had a significantly lower average round trip time than those from experiments 2 and 3 (O. mellicolor: 116,132 , and 137 seconds for experiments 1 , 2 and 3 respectively, Kruskall-Wallis test: $H_{2}=7.48, P=0.024 ; T$. dorsalis: 101, 124, and 143 seconds for experiments 1,2 and 3 respectively, Kruskall-Wallis test: $H_{2}=16.07$, $P<0.001)$. In experiment 1 more bees visited the same type during their first two visits than in experiments 2 and $3(80 \%$ and $65 \%$ respectively for $O$. mellicolor and $80 \%$ and $50 \%$ respectively for $T$. dorsalis). When only bees are taken into account that chose the same flower type during the first two visits, no significant differences in constancy between the experiments were found $\left(O\right.$. mellicolor: $\mathrm{CI}_{1} \pm$ $\mathrm{SD}=0.79 \pm 0.24, \mathrm{CI}_{2,3} \pm \mathrm{SD}=0.72 \pm 0.16$, Mann-Whitney U test: $U=41, N_{1,3}=13, N_{2}=$ $8, P=0.46 ; T$. dorsalis: $\mathrm{CI}_{1} \pm \mathrm{SD}=0.72 \pm$ $0.23, \mathrm{CI}_{2,3} \pm \mathrm{SD}=0.55 \pm 0.17$, Mann-Whitney U test: $U=23, N_{1,3}=10, N_{2}=8, P=0.15$ ).

Foraging tempo did not explain interspecific differences between $T$. dorsalis and $O$. mellicolor: when flowers differed only in colour, extra-patch time between the first two visits was shorter in $T$. dorsalis than in O. mellicolor (Mann-Whitney $\mathrm{U}$ test, $U=93.5, N_{1}=20, N_{2}=16, P=0.033$ ), whereas $T$. dorsalis was less constant than O. mellicolor.

\subsubsection{Colour preference}

In experiments 2 and 3, no general preference was found for yellow or blue (on average $39 \pm 20$ and $48 \pm 23 \%$ of visits to yellow flowers respectively). Although some individuals visited mainly yellow flowers and others mainly blue flowers, the nature of this preference (yellow or blue) did not affect the degree of constancy (Pearson correlation: $r=0.075$, $N=40, P=0.647)$. In experiment 1 , where individuals behaved more constantly, yellow flowers were significantly more visited than in experiments 2 and 3 (on average $75 \pm 30 \%$ visits to yellow flowers; ANOVA: $F_{2,57}=$ 11.11, $P<0.001$, Tukey HSD for comparisons between experiments: $P<0.004$ for each comparison). Colour preference did not differ between the species (ANOVA: $F_{1,58}=2.34$, $P=0.13$ ).

\section{DISCUSSION}

Both Oxytrigona mellicolor and Trigona dorsalis showed flower constant choice behaviour, in agreement with previous studies on stingless bees (Slaa et al., 1998a, b). Although the species differed in colony organisation and foraging strategy, there were no large species-specific differences, except for the effect of nestmates on flower constancy. This study shows that the individual degree of flower constancy is affected by both floral similarity and individual foraging tempo. Sugar concentration of the reward had relatively little effect on flower constancy, although an increase in sugar concentration enhanced flower constancy slightly in $T$. dorsalis. The presence of nestmates increased flower constancy in O. mellicolor but not in T. dorsalis, probably due to species-specific differences in local enhancement.

\subsection{Extrinsic foraging conditions}

This study shows that the degree of individual flower constancy is highly affected by the number of perceptual modalities in which the flower types differ. This expands the correlation of flower constancy with visual similarity (see Chittka et al., 1999, 2001) to a more general correlation with perceptual similarity, including olfactory cues. Moreover, it indicates that studies using natural flowers, in which potential odour emission is generally neglected, should be interpreted with care regarding floral similarity as perceived by the bees.

The fact that the level of constancy increased with increasing floral dissimilarity may suggest that floral discriminability was a limiting factor for constant foraging in these bees. Nevertheless, the stingless bees used in this study learned to discriminate quickly between equally scented yellow and blue flowers (within five visits) when only one of 
the two types was rewarding (unpublished data Slaa and Verhoeven), which indicates that colour discriminability was not a limiting factor in flower constancy. This suggests that stingless bees do not use all discriminable floral differences in flower constant foraging, which is in agreement with findings on honey bee foraging, where individuals rapidly learn to discriminate between blue and white flower types when they are differentially rewarding, but do not discriminate between these when they are equally rewarding (e.g. Wells et al., 1992; Hill et al., 2001).

Individual flower constancy was mostly unaffected by sugar concentration. The superfluous amounts of nectar offered in our experiments could have overshadowed the effect of sugar concentration, and further experiments with lower nectar amounts are required to establish the potential effect of sugar concentration on flower constancy.

When foraging in the presence of nestmates, O. mellicolor showed local enhancement whereas $T$. dorsalis did not, in concordance with previous findings for these species (Slaa et al., 2003). Although individuals of $O$. mellicolor tended to land close to a nestmate, colour preference was stronger than the tendency to land on an occupied flower. This is in agreement with findings by Biesmeijer and Vork (1997) for the stingless bee Melipona fasciata. In addition to the physical presence, foragers can also indirectly attract nestmates through scent marks left on visited flowers (Villa and Weiss, 1990; Stout and Goulson, 2001). If this ever occurred in our experiments, the test bee would not only have reacted to scent marks left by her nestmates, but most probably also to her own scent marks. However, individuals foraging alone on the patch visited many different flowers of the same type instead of returning to the same individual flower. Of the individuals choosing the same flower type during their first two visits to the patch (when flowers are clean and can only contain scent marks from the first trip), $73 \%$ (O. mellicolor) and 80\% (T. dorsalis) visited a different flower of the same type. This indicates that in our experiments scent marking of individual flowers was not a common mechanism in locating highly rewarding flowers.

\subsection{Intrinsic factors}

Flower choices were clearly affected by individual foraging tempo. The effect of extrapatch time on flower choice is probably related to the time-dependent processes of memory formation and information retrieval (Menzel, 1999). In A. mellifera, choice between a learned colour and a new colour after a single learning trial was dependent on the time interval between learning and testing, due to rapid information loss from the short-term memory over time (reviewed in Menzel, 1999). After three learning trials, however, subsequent flower choice was no longer influenced by the visit intervals, probably due to the formation of other, longer lasting, memories (Menzel, 1999). This coincides with our observations that the temporal effect on successive flower choice only holds for the first choices. When foragers visit more than one flower on each trip, time intervals between successive flower choices will typically be shorter than those experienced in this study, but have been found to affect flower choice similarly: time intervals between successive flower choices within a single foraging trip were shorter for constant flights than for inconstant flights (Greggers and Menzel, 1993; Chittka et al., 1997), possibly related to quicker information retrieval from the short-term memory than from the long-term memory.

Although flower constancy was related to extra-patch times between the first two flower choices, these temporal effects could explain only part of the variability in flower constancy. Other intrinsic factors that vary among individuals, such as previous foraging experience and age (Giurfa et al., 1995; Ray and Ferneyhough, 1997; Gumbert, 2000) and learning speed (Brandes, 1988; Brandes and Menzel, 1990) may also influence the individual degree of flower constancy. In addition, colony condition and the availability of natural food sources may affect flower choice. These factors could have contributed to the differences in flower constancy between experiment 1 (which was conducted in the dry season of 1998) and experiments 2 and 3 (which were conducted in the wet season of 2000). Nevertheless, it is unlikely that the observed differences within each experiment 
were due to changes in colony conditions and/or season because each experiment was conducted within a short time range (max. 3 months).

\subsection{Inter-specific differences in flower constancy}

Inter-specific comparisons among studies are hampered by the fact that the level of flower constancy can be highly influenced by the specific foraging situation, as we demonstrated in this study. The effect of floral similarity and sugar concentration of the nectar was similar for both species, which suggests that the effects of these factors are independent of species. The effect of nestmates on flower constancy was species-dependent, and only the species that showed local enhancement $(O$. mellicolor) was affected by the presence of nestmates. Although $O$. mellicolor foraged significantly more constant under equal foraging conditions than $T$. dorsalis, the differences were small and should be re-confirmed by using more than one colony per species.

When we compare stingless bees (this study) with honey bees foraging under similar conditions (studies by Wells and colleagues), honey bees seem to be much more constant when flower types differ only in colour or odour, but differences are largely reduced when flower types differ in both odour and colour. Therefore, inter-specific differences are not easily captured in a single experiment, and should be evaluated for different foraging conditions. Because natural flowers often differ in more than one cue, stingless bees may be as constant as honeybees under natural foraging conditions.

\section{ACKNOWLEDGEMENTS}

We thank I. van Veen for collecting part of the data, and J.C. Biesmeijer, M. Giurfa and an anonymous referee for critical comments on previous versions of the manuscript. This work was made possible through the Programa de Apicultura y Meliponicultura (PRAM), financed by the Netherlands Organization for Cooperation in Higher Education (Nuffic), and a scholarship to A.J.M.T. from the Lucie Burgers Foundation for Comparative Research, Arnhem, The Netherlands.
Résumé - Effet de facteurs intrinsèques et extrinsèques sur la constance florale des abeilles sans aiguillon. Nombreux sont les insectes visitant les fleurs qui présentent une certaine constance florale. Ce comportement est très flexible et une forte variabilité inter et intra-spécifique a été mentionnée. Cette variabilité complique grandement à la fois l'analyse de la constance florale propre à chaque espèce et les comparaisons inter-spécifiques. Malheureusement, les causes et les mécanismes de la constance florale restent largement inconnus. Afin d'améliorer notre compréhension de la variabilité de ce comportement, nous avons étudié l'influence de trois facteurs du milieu sur le niveau de constance florale individuelle : (i) la concentration en sucres, (ii) la présence de membres de la colonie sur les fleurs et (iii) la similitude des types floraux. Pour tester si ces influences étaient propres à l'espèce, nous avons utilisé deux espèces d'abeilles sans aiguillon, Trigona dorsalis et $O x y$ trigona mellicolor, qui sont très semblables d'apparence mais possèdent une organisation de la colonie et une stratégie de butinage différentes. Les abeilles pouvaient butiner sur une zone de fleurs artificielles comprenant deux types de fleurs qui offraient la même récompense. Lorsque les types floraux ne différaient que par la couleur, les deux espèces d'abeilles n'étaient que modérément constantes ; néanmoins $O$. mellicolor l'était un peu plus que $T$. dorsalis (Fig. 4). La constance florale a nettement augmenté pour les deux espèces d'abeilles lorsque les types floraux se ressemblaient moins et les niveaux de constance approchaient alors ceux des abeilles domestiques européennes (Fig. 3). La qualité de la récompense a eu peu d'effet sur le comportement de choix de la fleur lorsque les deux types floraux offraient des récompenses égales (Fig. 1). La présence de membres de la colonie a amélioré un peu la constance florale chez $O$. mellicolor mais pas chez T. dorsalis (Fig. 2), probablement à cause de différences propres à l'espèce dans l'amélioration locale. Nous avons observé une forte variabilité individuelle au sein des traitements ; cette variabilité s'explique en partie par la variation individuelle du temps passé loin de la zone de butinage entre les premières visites. La probabilité de revisiter le même type floral à la seconde visite a diminué quand le temps passé hors de la zone de butinage augmentait et la constance globale a été significativement influencée selon que les deux premières visites avaient lieu sur le même type floral ou non (Fig. 4). Cette étude montre que la variabilité individuelle est affectée à la fois par des facteurs extrinsèques (la similitude florale et la présence de membres de la colonie) et par des facteurs intrinsèques (le rythme de butinage). Il faudrait prendre en compte ces sources de variabilité intra-spécifiques lorsqu'on établit un degré de constance florale propre à une espèce et quand on compare des espèces.

constance florale / conditions de butinage / abeille sans aiguillon 
Zusammenfassung - Wirkung von inneren und äußeren Faktoren auf die Blütenstetigkeit von stachellosen Bienen. Viele blütenbesuchenden Insekten zeigen einen gewissen Grad von Blütenstetigkeit. Dieses Verhalten ist sehr flexibel und es wurde eine hohe inter- und intra-spezifische Variabilität beschrieben, durch die sowohl die artspezifische Analyse der Blütenstetigkeit als auch der Vergleich zwischen den Arten in hohem Maße kompliziert ist. Leider sind die Ursachen und der Mechanismus der Blütenstetigkeit weitgehend unbekannt. Um die Variabilität der Blütenstetigkeit besser zu verstehen, untersuchten wir 3 Umwelteinflüsse auf die individuelle Stetigkeit: (1) die Zuckerkonzentration, (2) die Anwesenheit von Stockgenossen auf den Blüten, und (3) Ähnlichkeit der Blütenarten. Um zu testen, ob diese Einflüsse artspezifisch sind, arbeiteten wir mit 2 Arten Stachelloser Bienen, Trigona dorsalis und Oxytrigona mellicolor, die in ihrer äußeren Erscheinung sehr ähnlich, in ihrer Organisation im Nest und in der Sammelstrategie aber sehr unterschiedlich sind. Die Bienen konnten auf einem Blütenareal sammeln, das aus 2 Blütentypen bestand, die beide die gleiche Belohnung abgaben. Wenn sich die Blütentypen nur in der Farbe unterschieden, war die Stetigkeit beider Arten nur mäßig, $O$. mellicolor erwies sich jedoch als ein wenig stetiger als $T$. dorsalis (Abb. 4). Bei beiden Arten nahm die Blütenstetigkeit stark zu, wenn die Blüten sich deutlicher unterschieden, wobei sie sich dem Grad annäherten, der bei Europäische Honigbienen gefunden wurde (Abb. 3). Die Qualität der Belohnung hatte nur einen geringen Einfluss auf das Wahlverhalten, wenn beide Blütentypen die gleiche Belohnung anboten (Abb. 1). Die Anwesenheit von Stockgenossinnen erhöhte die Blütenstetigkeit bei $O$. mellicolor in einem geringen Maß, aber nicht bei $T$. dorsalis (Abb. 2), vermutlich auf Grund von artspezifischen Unterschieden bei der lokalen Verstärkung. Wir beobachteten eine hohe individuelle Variabilität innerhalb der Versuche. Diese Variabilität erklärt sich zum Teil mit der individuellen Variation in der Zeit, die ein Tier nach dem ersten erfolgreichen Besuch dem Blütenareal fern blieb. Die Wahrscheinlichkeit, denselben Blütentyp beim 2. Besuch anzufliegen, nahm mit der längeren Abwesenheit vom Blütenareal ab. Insgesamt bestand ein signifikanter Einfluss durch die Natur der ersten beiden Versuche auf die Stetigkeit (zu gleichen oder nicht gleichen Blütentypen; Abb. 4). Diese Untersuchung zeigt, dass eine individuelle Variabilität sowohl durch äußere Faktoren (i.e. Ähnlichkeit der Blüten und Anwesenheit von Stockgenossinnen) als auch innere Faktoren (i.e. die Geschwindigkeit beim Sammeln) verursacht wird. Diese Grundlagen von innerartlicher Variabilität sollte berücksichtigt werden, (1) bei der Feststellung der artspezifischen Blütenstetigkeit und (2) wenn Arten miteinander verglichen werden.

Blütenstetigkeit / Trachtverhältnisse / Stachellose Bienen

\section{REFERENCES}

Banschbach V.S. (1994) Colour association influences honey bee choice between sucrose concentrations, J. Comp. Physiol. A 175, 107-114.

Bateman A.J. (1951) The taxonomic discrimination of bees, Heredity 5, 271-278.

Biesmeijer J.C., Vork W. (1997) Flower constancy in stingless bees: the effect of patch position, odour and the presence of other bees on individual decision-making by Melipona fasciata foragers, in: Biesmeijer J.C. (Ed.), The organisation of foraging in stingless bees of the genus Melipona, Ph.D. Thesis, Utrecht University, The Netherlands, pp. 171-188.

Brandes C. (1988) Estimation of heritability of learning behaviour in honeybees (Apis mellifera capensis), Behav. Genet. 18, 119-132.

Brandes C., Menzel R. (1990) Common mechanisms in proboscis extension conditioning and visual learning revealed by genetic selection in honeybees (Apis mellifera capensis), J. Comp. Physiol. A 166, 545-552.

Chittka L., Gumbert A., Kunze J. (1997) Foraging dynamics of bumble bees: correlates of movements within and between plant species, Behav. Ecol. 8, 239-249.

Chittka L., Thomson, J.D., Waser N.M. (1999) Flower constancy, insect psychology, and plant evolution, Naturwissenschaften 86, 361-377.

Chittka L., Spaethe J., Schmidt A., Hickelsberger A. (2001) Adaptation, constraint, and chance in the evolution of flower color and pollinator color vision, in: Chittka L., Thomson J.D. (Eds.), Cognitive ecology of pollination, Cambridge University Press, Cambridge, UK, pp. 106-126.

Darwin C. (1876) The effects of cross and self fertilisation in the vegetable kingdom, John Murray, London.

Frisch K. von (1919) Über den Geruchsinn der Biene und seine blütenbiologische Bedeutung, Zool. Jahrb. 37, 1-238.

Giurfa M., Núñez J., Chittka L., Menzel R. (1995) Colour preferences of flower-naïve honeybees, J. Comp. Physiol. A 177, 247-259.

Goulson D., Wright N.P. (1998) Flower constancy in the hoverflies Episyrphus balteatus (Degeer) and Syrphus ribessi (L.) (Syrphidae), Behav. Ecol. 9, 213-219.

Goulson D., Ollerton J., Sluman C. (1997) Foraging strategies in the small skipper butterfly, Thymelicus flavus: when to switch?, Anim. Behav. 53, 1009-1016.

Grant V. (1950) The flower constancy of bees, Bot. Rev. 16, 379-398.

Greggers U., Menzel R. (1993) Memory dynamics and foraging strategies of honey bees, Behav. Ecol. Sociobiol. 32, 17-29.

Gumbert A. (2000) Color choices by bumble bees (Bombus terrestris): innate preferences and 
generalization after learning, Behav. Ecol. Sociobiol. 48, 36-43.

Hill P.S.M., Wells P.H., Wells H. (1997) Spontaneous flower constancy and learning in honey bees as a function of colour, Anim. Behav. 54, 615-627.

Hill P.S.M., Hollis J., Wells H. (2001) Foraging decisions in nectarivores: unexpected interactions between flower constancy and energetic rewards, Anim. Behav. 62, 729-737.

Hubbell S.P., Johnson L.K. (1978) Comparative foraging behavior of six stingless bee species exploiting a standardized resource, Ecology 59, 1123-1136.

Johnson L.K. (1983) Foraging strategies and the structure of stingless bee communities in Costa Rica, in: Jaisson P. (Ed.), Social insects in the tropics, Vol. 2, Paris, Univ. Paris Nord, pp. 31-58.

Laska M., Galizia C.C., Giurfa M., Menzel R. (1999) Olfactory discrimination ability and odor structure-activity relationships in honeybees, Chem. Senses 24, 429-438.

Menzel R. (1999) Memory dynamics in the honeybee, J. Comp. Physiol. A 185, 323-340.

Propoky R.J., Miller N.W., Duan J.J., Vargas R.I. (2000) Local enhancement of arrivals of Ceratitis capitata females on fruit mimics, Entomol. Exp. Appl. 97, 211-217.

Raveret Richter M. (2000) Social wasp (Hymenoptera: Vespidae) foraging behavior, Annu. Rev. Entomol. 45, 121-150.

Ray S., Ferneyhough B. (1997) The effects of age on olfactory learning and memory in the honey bee Apis mellifera, Neuro Rep. 8, 789-793.

Roubik D.W. (1983) Nest and colony characteristics of stingless bees from Panamá (Hymenoptera: Apidae), J. Kans. Entomol. Soc. 56, 327-355.

Slaa E.J. (2003) Foraging ecology of stingless bees: From individual behaviour to community ecology, Ph.D. Thesis, Utrecht University, The Netherlands.

Slaa E.J., Cevaal A., Sommeijer M.J. (1998a) Flower constancy in Trigona stingless bees foraging on artificial flower patches: a comparative study, J. Apic. Res. 37, 191-198.

Slaa E.J., Ruiz B., Salas R., Zeiss M., Sommeijer M.J. (1998b) Foraging strategies of stingless bees: Flower constancy versus optimal foraging?, Proc. Exp. Appl. Entomol. 9, 185-190.

Slaa E.J., Wassenberg J., Biesmeijer J.C. (2003) The use of field-based social information in eusocial foragers: Local enhancement among nestmates and hetero-specifics in stingless bees, Ecol. Entomol. 28, 369-379.

Stout J.C., Goulson D. (2001) The use of conspecific and interspecific scent marks by foraging bumble bees and honey bees, Anim. Behav. 62, 183-189.

Thorpe W.H. (1956) Learning and instinct in animals, Methuen and Co., London, UK.

Villa J.D., Weiss M.R. (1990) Observations on the use of visual and olfactory cues by Trigona spp. foragers, Apidologie 21, 541-545.

Waddington K.D., Holden L.R. (1979) Optimal foraging: on flower selection by bees, Am. Nat. 114, 179-196.

Waser N.M. (1986) Flower constancy: definition, cause, and measurement, Am. Nat. 127, 593-603.

Wells H., Rathore R.R.S. (1994) Foraging ecology of the Asian hive bee, Apis cerana indica, within artificial flower patches, J. Apic. Res. 33, 219230.

Wells P.H., Wells H. (1984) Can honeybees change foraging patterns?, Ecol. Entomol. 9, 467-473.

Wells H., Hill P.S., Wells P.H. (1992) Nectarivore foraging ecology: rewards differing in sugar types, Ecol. Entomol. 17, 280-288. 